\title{
Contabilidade de Custos na Administração Pública: O Estabelecimento dos Gastos de Posse Estratégica na Marinha do Brasil
}

\author{
Anderson Soares da Silva, Marcelo David Davis e \\ Alexandre Rodrigues Viveiros
}

\section{Histórico}

A busca pelo aperfeiçoamento administrativo do aparelho estatal no Brasil não é um fato recente. Porém, nos últimos anos o tema da eficiência do Estado vem assumindo cada vez mais um papel de relevância dentro da nossa sociedade.

Pereira (2006) afirma que a globalização, além de afetar as organizações privadas, acabou por atingir de forma semelhante a administração pública, gerando questionamentos sobre seu modelo. Tais questionamentos têm demandado a busca de novas soluções a fim de atender a um cidadão cada vez mais informado e, por conseguinte, exigente.

Nesse contexto, entra em cena a questão da qualidade do gasto público, em que a eficiência da administração pública torna-se essencial, dada a necessidade de redução de custos e de aumento da qualidade dos serviços prestados aos cidadãos. A afirmação anterior encontra respaldo no pensamento de Schwengber (2007) ao afirmar que um dos três níveis de análise da qualidade do gasto público 
é a eficiência com que, uma vez alocados os recursos públicos entre as distintas funções do Governo, estes são transformados em bens e serviços públicos. Segundo o referido autor, nesse nível, qualidade implicaria eficiência na utilização de recursos públicos.

Schwengber (2007) afirma ainda que:

Duas questões estão no centro de qualquer diagnóstico sobre a qualidade do gasto público: i) quanto menos o Governo poderia gastar para atingir os mesmos resultados; ii) quanto melhor poderiam ser os resultados, dado os níveis atuais de gasto público. As metodologias não-paramétricas permitem responder a essas questões uma vez que mensuram as diferenças de produtividade e eficiência entre as unidades administrativas.

Assim, a difusão de doutrinas de gestão pública voltadas para os resultados, nos últimos anos, indica a necessidade da institucionalização de uma atividade de planejamento e controle fundamental para a avaliação dos gestores públicos, que é o controle gerencial, com ênfase na análise dos custos das organizações públicas. Entretanto, nota-se que ainda hoje o número de pesquisas sobre custos no Brasil é relativamente pequeno, em especial no setor público, fato esse que aponta para a necessidade da realização de mais estudos exploratórios na área.

Dessa forma, a Marinha do Brasil $(\mathrm{MB})$, por meio das iniciativas propostas pelo Governo federal nos últimos anos, percebeu a necessidade de substituição da administração pública burocrática pela administração gerencial, criando um sistema para a gestão de suas Organizações Militares Prestadoras de Serviços (OMPS).
Entretanto, as recentes restrições orçamentárias, impostas às Forças Armadas, geraram a necessidade de a MB conhecer o nível necessário de comprometimento dos recursos orçamentários a ela provi-sionados com a manutenção e funcionamento das estruturas das OMPS em um cenário de inexistência de serviços a serem prestados ou com um nível de atividade próximo de zero. Essa informação deveria ser levada em consideração a fim de possibilitar um melhor planejamento dos recursos orçamentários a serem destinados àquelas organizações militares, as quais se relacionam, basicamente, com a manutenção dos meios navais.

Apesar das relevantes conquistas alcançadas nos últimos anos pela $\mathrm{MB}$ em relação ao controle de custos em suas OMPS, os dados necessários à obtenção da informação não haviam sido previstos no arcabouço conceitual inicial do sistema de gestão das OMPS (Sistema OMPS).

Pelo motivo acima exposto, a Diretoria de Finanças da Marinha (DFM), órgão central de contabilidade da Marinha, passou a desenvolver estudos na busca do valor adequado desse montante, o qual foi denominado Gastos de Posse Estratégica (GPE). Em síntese, perquiriu-se qual seria o volume de recursos orçamentários necessários para manter uma OMPS, na hipótese de que nenhum cliente encomendasse qualquer produto ou serviço. A resposta a essa questão demandaria informações das parcelas fixas e variáveis dos gastos, as quais não se encontram disponíveis hoje nas OMPS e no Sistema Integrado de Administração Financeira do Governo Federal (Siafi), uma vez que este último e o Sistema OMPS não prevêem a obrigatoriedade de os gastos serem registrados e mensurados como fixos e variáveis. 
Assim sendo, o presente trabalho versa sobre como foi possível, diante das limitações existentes, obter os GPE e utilizá-los como indicadores de desempenho das OMPS, em especial analisar os impactos da introdução destes no Relatório EconômicoFinanceiro (REF) daquelas OMPS da Marinha do Brasil, encaminhados trimestralmente à Alta Administração Naval pela DFM.

Com o propósito de propiciar um melhor entendimento do problema de pesquisa, na próxima seção serão apresentados os principais aspectos conceituais do Sistema OMPS.

\section{Sistema OMPS}

O Sistema OMPS foi implantado no âmbito da Marinha do Brasil objetivando solucionar a preocupação existente na Alta Administração Naval, quanto à incapacidade de mensuração dos custos das organizações militares industriais e prestadoras de serviços (MARINHA Do BRAsIL, 2004b).

Tal preocupação encontrava origem, principalmente, nos seguintes fatos:

a) constantes déficits financeiros dessas organizações; e

b) desconhecimento de outras posições econômico-patrimoniais que possibilitassem a identificação e a correta avaliação das diversas atividades desenvolvidas $(\mathrm{MB}$, 2004b, p.15).

Diante de tal cenário, percebeu-se a necessidade de criação de um sistema que permitisse:

a) Conhecimento dos gastos efetivos de operação dessas organizações, separados em custos de produção/prestação de serviços e gastos inerentes às atividades administrativas; e

b) Gerência dos ativos, isto é, domínio perfeito das disponibilidades financeiras, conhecimento dos faturamentos efetuados e da imobilização dos estoques (MB, 2004b).

Assim, a Marinha criou as Organizações Militares Prestadoras de Serviços (OMPS) e o Sistema OMPS, no ano de 1994, na busca do aprimoramento dos controles internos e da determinação mais eficiente dos custos das organizações militares industriais e prestadoras de serviços (MB, 2004b, p.15).

“...a difusão de doutrinas de gestão pública voltadas para os resultados, nos últimos anos, indica a necessidade da institucionalização de uma atividade de planejamento e controle fundamental para a avaliação dos gestores públicos, que é o controle gerencial..."

Para operacionalizar a implantação do sistema foram utilizadas duas ferramentas: o Siafi e a Contabilidade de Custos.

Especificamente em relação ao Siafi, destaca-se que a sua implantação significou uma inovação sem precedentes na operacionalização do fluxo financeiro no Governo federal, materializado na conta única do Tesouro Nacional, o que permitiu 
uma perfeita racionalização na utilização dos recursos financeiros.

No que se refere à contabilidade de custos, a MB, por ocasião da adoção do Sistema OMPS, pautou-se no método de custeio denominado "tradicional" ou "por absorção", em virtude de esse método apropriar todos os custos incorridos na produção aos produtos/serviços que a OMPS produziu/prestou no período de apuração de custos (BRASIL, 2004a, p.15).

A utilização dessas ferramentas permitia que a Alta Administração Naval passasse a visualizar tanto os reais custos dos serviços prestados por aquelas organizações quanto a necessidade estratégica de suas existências (MB, 2004b, p.15).

Conceitualmente, OMPS é a organização militar que presta serviços a outras organizações militares e, eventualmente, a organizações extra-Marinha em uma das seguintes áreas: industrial, de ciência e tecnologia, hospitalar, de abastecimento e de serviços especiais, efetuando a cobrança pelos serviços prestados, a partir dos custos e despesas por ela incorridos (MB, 2004b, p.15-2).

Para a contratação de uma OMPS, as Organizações Militares (OM) clientes deverão emitir um Pedido de Serviço (PS), ou documento similar, especificando o serviço a ser executado. Em seguida, a OMPS emitirá os orçamentos dos serviços solicitados que, caso aprovados pelas $\mathrm{OM}$ clientes, implicará a imediata indicação e comprometimento dos recursos, na forma escritural, antes do início da execução dos serviços, como garantia do seu pagamento após a conclusão.

Assim, é possível perceber que, à semelhança das empresas privadas, o relacionamento do tipo "fornecedor $x$ cliente" passou a ser buscado pelas OMPS.
Vale ressaltar que uma OMPS não visa lucro, pois oneraria a própria Marinha que é o seu principal cliente, devendo, portanto, faturar o necessário para cobrir os seus gastos, de acordo com o preconizado nas normas internas da Marinha.

Assim, segundo Fonseca (2003):

Os três grandes méritos do Sistema OMPS são: dar ênfase à apuração de custos, como ferramenta imprescindível para a gestão; preencher uma lacuna hoje existente na teoria da Contabilidade Pública, quanto ao tratamento dos custos na administração pública; e disponibilizar, para a sociedade, informações de custos referentes ao emprego do numerário utilizado pelas OMPS.

A fim de evidenciar a tão necessária transparência desse processo, a Marinha usa contas contábeis, códigos, eventos do plano de contas e tabela de eventos do Siafi, tendo a Secretaria do Tesouro Nacional (STN) criado, a pedido da Marinha, contas, códigos e eventos específicos para atender ao Sistema OMPS.

Cabe ressaltar que periodicamente são realizadas auditorias pelos órgãos especializados da Marinha - Diretoria de Finanças e Diretoria de Contas -, nas quais são expedidos relatórios com não conformidades observadas, a serem sanadas em prazos estabelecidos.

Além disso, as OMPS estão sujeitas ao controle do Tribunal de Contas da União, que recebe anualmente as contas dessas organizações para análise.

A criação do Sistema OMPS pode ser apontada como ponto de partida de uma mudança cultural dentro da Marinha, podendo servir como alternativa para solução de inúmeros problemas que afetam o serviço público. (MB, 2004b, p.15). 
Como confirmação do potencial de sucesso do Sistema OMPS, no ano de 1999 foi um dos 18 projetos vencedores entre os 78 inscritos, no total, para a $4^{\text {a }}$ edição do Concurso de Inovações na Gestão Pública - Prêmio Hélio Beltrão, promovido pelo Ministério do Planejamento, Orçamento e Gestão e pelo Instituto Hélio Beltrão.

\section{Relevância do tema}

As tentativas de verificação empírica da aplicação de conceitos teóricos oriundos do ambiente acadêmico são valiosas tanto para os teóricos quanto para os práticos de qualquer área do conhecimento humano. Tais tentativas configuram-se como uma das melhores formas de avaliação e correção dos rumos, na concepção e na transmissão do conhecimento teórico, a fim de materializá-lo em termos práticos.

Cabe aqui ressaltar que quando uma dessas tentativas refere-se a uma área de conhecimento vital para o êxito de organizações que dão sustentação à nossa sociedade, a sua relevância fica ainda maior.

Nesse sentido, o controle de custos pode ser apontado como um dos fatores críticos para o sucesso de qualquer organização. No entanto, essa preocupação não deve ficar restrita ao setor privado, ao contrário, deve ser essencial na área pública, onde problemas de falta de recursos são acentuados diante das demandas da sociedade.

Configura-se, dessa forma, a importância da contabilidade de custos dentro do ambiente público, que tem na sociedade, ao mesmo tempo, sua cliente e proprietária, e que cada vez mais exige um comportamento adequado de seus agentes a fim de que se obtenha a efetividade da gestão pública no país.

Assim, o tema abordado se reveste de importância teórica, tendo em vista que o assunto estudado se revela enriquecedor da moderna literatura voltada para a administração pública, ao constatarmos o pequeno número de trabalhos acadêmicos com foco na análise e na compreensão dos sistemas de custos utilizados pelas organizações da esfera pública.

Além disso, destaca-se o fato de que grande parte da sociedade brasileira mal conhece as Forças Armadas, bem como seus métodos de administração, pois a maior parte da literatura que aborda essa vertente $d a$ sociedade fica praticamente restrita a alguns grupos de pessoas com relações diretas com o meio militar e seus centros de estudo.

Pode-se depreender, então, que a exigüidade de trabalhos acadêmicos sobre modelos administrativos militares brasileiros torna o tema vasto, passível de ser explorado, a fim de lançar novas perspectivas que possam levar mais pesquisadores a buscar novas formas de compreender e interpretar os sistemas de custos adotados pelas organizações do setor público.

\section{Problema e objetivos de pesquisa}

Vergara (2003, p.21) dá a seguinte definição para problema: "é uma questão não resolvida, é algo para o qual se vai buscar resposta, via pesquisa". A referida autora (op.cit., p.21) afirma que:

Uma questão não resolvida pode estar referida a alguma lacuna epistemológica ou metodológica percebida, a alguma dúvida quanto à sustentação de uma afirmação geralmente aceita, a alguma necessidade de pôr à prova 
uma suposição, a interesses práticos, à vontade de compreender e explicar uma situação do cotidiano ou outras situações.

Assim, o problema a ser respondido pela presente pesquisa é como a Diretoria de Finanças da Marinha conseguiu estabelecer um novo indicador de desempenho das OMPS, diante da necessidade da Alta Administração Naval de saber qual seria o montante de recursos financeiros a ser disponibilizado para a sobrevivência dessas organizações, em uma situação na qual o nível de suas atividades fosse próximo de zero?

Se o problema é uma questão a investigar, o objetivo é um resultado a alcançar (Vergara, 2003, p.25).

De acordo com a classificação dessa autora, o objetivo final, quando alcançado, dá resposta ao problema. Já os objetivos intermediários "são as metas de cujo atingimento depende o alcance do objetivo final".

Seguindo o que nos ensina Vergara (2003), o objetivo final deste estudo foi verificar como se tornou possível, diante das limitações existentes, obter os GPE e utilizá-los como indicadores de desempenho das OMPS no Relatório EconômicoFinanceiro (REF) das OMPS da Marinha do Brasil, encaminhados trimestralmente à Alta Administração Naval pela DFM.

Com isso, pretende-se possibilitar um aprofundamento dos conhecimentos sobre custos existentes na área pública, através de estudos empíricos sobre o funcionamento das OMPS.

Os objetivos intermediários são: revisar a literatura sobre contabilidade de custos; descrever as principais características do Sistema OMPS; e apresentar novos caminhos para avaliação de organizações públicas, levando-se em consideração seu custo fixo de manutenção.

\section{Justificativa da pesquisa}

A presente pesquisa justifica-se pela mais recente demonstração de alinhamento da Marinha com as idéias governamentais. No início de 2007, começa a implantação de uma iniciativa de excelência de gestão denominada Programa Netuno, que guarda estreita relação com o programa Gespública, estabelecido no âmbito federal pelo Decreto $n^{\circ}$ 5.378/2005.

De acordo com o referido diploma legal, a finalidade do Gespública é:

Contribuir para a melhoria da qualidade dos serviços públicos prestados aos cidadãos e para o aumento da competitividade do País, formulando e implementando medidas integradas em agenda de transformações da gestão, necessárias à promoção dos resultados preconizados no plano plurianual, à consolidação da administração pública profissional voltada ao interesse do cidadão e à aplicação de instrumentos e abordagens gerenciais (Gespública, 2005).

Além disso, justifica-se também pelo contido na Carta de Brasília, emitida pelo Ministério de Planejamento, Orçamento e Gestão (MP), em conjunto com o Conselho Nacional de Secretários Estaduais de Administração (Consad), por ocasião do Congresso desse Conselho, realizado em maio de 2008, em que as citadas instituições alertam para a necessidade de se alcançar melhores resultados para a sociedade com maior qualidade do gasto público, ou seja, com a otimização da aplicação dos recursos disponíveis. 


\section{Organização do estudo}

O presente estudo encontra-se organizado em cinco capítulos. $\mathrm{Na}$ introdução, buscou-se realizar a contextualização do tema, bem como demonstrar sua relevância e os motivos que justificaram a execução da pesquisa. Além disso, foram elencados os objetivos que se pretende alcançar, visando responder ao problema de pesquisa formulado.

O segundo capítulo tem por objetivo apresentar o construto teórico utilizado na pesquisa, que alicerçará o estudo por meio de uma revisão bibliográfica com ênfase em contabilidade de custos e na administração pública, por constituírem as pedras basilares da pesquisa. Foi abordada a teoria relativa à contabilidade de custos, apresentando-se algumas abordagens consideradas como referência à análise de custos em relação ao volume de atividades. No terceiro capítulo foram considerados os aspectos metodológicos, a partir dos quais a pesquisa foi delineada. A caracterização do caso da definição dos GPE pela DFM, abordando os aspectos relativos ao seu desenvolvimento, consta no quarto capítulo.

Por fim, na última parte deste estudo foram expostas as considerações finais, segundo uma análise dos resultados encontrados na pesquisa, bem como da formulação das conclusões e recomendações.

\section{Referencial teórico}

\section{A contabilidade de custos}

A contabilidade de custos é definida por Horngren et al (2000, p.2) como o segmento da contabilidade que tem a função de mensurar e reportar informações financeiras e não-financeiras relativas à aquisição ou ao consumo de recursos da organização. Já Maher (1997) define contabilidade de custos como "o campo de Contabilidade que mensura e fornece informações sobre custos."

Assim, ao analisarmos as duas definições é possível depreender que o principal produto da contabilidade de custos é a informação de custos, que pode ser gerada por meio de dados financeiros

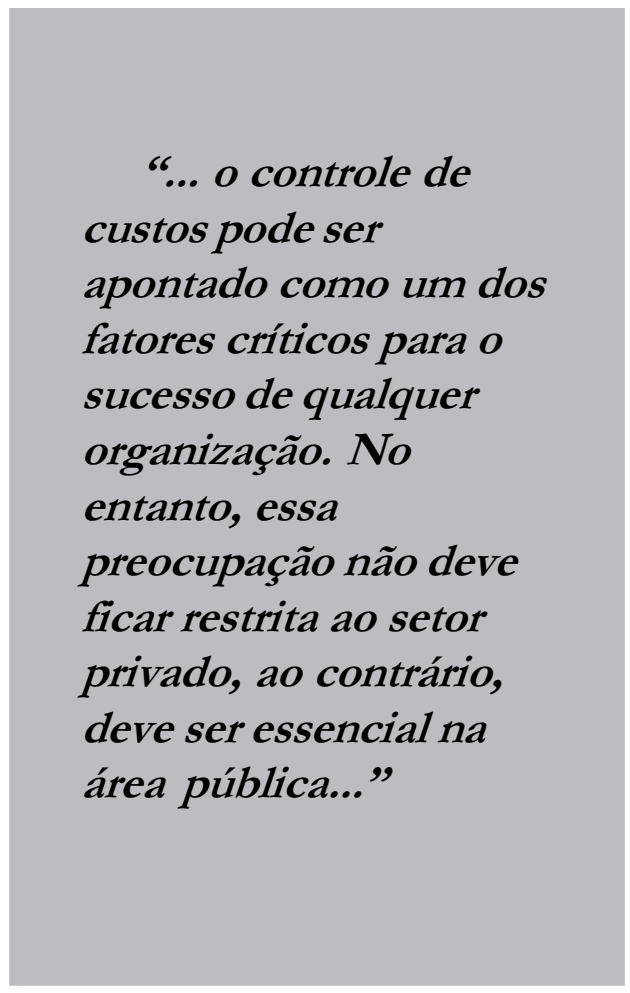

e não-financeiros. Ressaltando-se que as informações geradas pela contabilidade de custos devem atender tanto às determinações legais para a confecção das Demonstrações Contábeis quanto às necessidades gerenciais (FonseCA, 2003, p.13).

Backer e Jacobsen (1974, p. 2) afirmam que a contabilidade de custos tem três finalidades principais: 
a) fornecer dados para a avaliação dos estoques e a determinação dos lucros;

b) fornecer informações para o controle (relatórios de controle e de desempenho); e

c) prover dados para o planejamento e a tomada de decisões (política de preços, decisões de investimento, etc.)

Cada uma dessas finalidades busca informações diferentes, visando às diversas necessidades dos usuários da contabilidade de custos. Se os dados gerados para uma finalidade forem empregados para outra, é possível chegar a conclusões insatisfatórias e inadequadas (FONSECA, 2003, p.14).

Leone (2000) afirma que existem vários tipos de custos, e que essa diversidade existe para atender às diferentes necessidades gerenciais que foram surgindo com o passar dos anos. Tal afirmação encontra respaldo no pensamento de Horngren et al (2000) ao afirmar que existem custos diferentes para objetivos diferentes.

Assim, diante do objetivo do presente trabalho, será apresentada a classificação de custos quanto ao comportamento em relação ao volume de atividade, que dará o embasamento teórico para o desenvolvimento da pesquisa.

\section{Custos em relação ao volume de atividade}

Segundo Leone (2000, p.71), "todo custo, dentro da empresa, instituição, atividade ou processo, observa um comportamento definido diante de uma base de volume (parâmetro)".

$\mathrm{Na}$ classificação de custos em relação ao volume de atividades, podem ser divididos em dois grandes grupos: custos fixos e custos variáveis (FONSECA, 2003).
Leone (2000, p.71) afirma que:

os termos fixo e variável são geralmente usados para descrever como um custo reage às mudanças na atividade. Um custo variável é um custo que é proporcional ao nível da atividade (o custo total aumenta à medida que a atividade aumenta) e um custo fixo é constante no total, na faixa de volume relevante da atividade esperada que está sendo considerada.

Ainda sobre o conceito de custos fixos e variáveis, vale mencionar a definição dada pelo Conselho Regional de Contabilidade (CRC), seção São Paulo, conforme a seguir:

a) custos fixos: são aqueles que dentro de um período de tempo determinado, e para uma certa capacidade instalada, não variam, independentemente do volume de atividade desenvolvido pela empresa. Os custos fixos podem ainda ser divididos em: custo fixo de capacidade - custo referente à capacidade instalada da empresa, como, por exemplo, a depreciação; e custo fixo operacional - custo referente à operação das instalações, como, por exemplo, o imposto predial (CRC SP, 1992, p.19);

b) custos variáveis: são aqueles custos cujo valor total se modifica de forma diretamente proporcional à quantidade produzida (CRC - SP, 1992, p.19).

Alinhados com as definições anteriores, Horngren et al (2000, p.21) afirmam que um custo é variável quando "se altera em montante, em proporção às alterações num direcionador de custo", e que um custo é fixo quando "não se altera em 
montante, apesar das alterações num direcionador de custo".

Os mesmos autores (op. cit.) ressaltam que não se deve pensar que os custos podem ser exclusivamente fixos ou variáveis, dando o exemplo do caso relativo à mão-de-obra. Horngren et al (2000) defendem, assim, que, no caso em que os trabalhadores são pagos por peça produzida, a mão-de-obra é um custo totalmente variável. Por outro lado, quando o trabalho é por expediente, o custo da mão-de-obra é adequadamente classificado como fixo.

\section{Apuração de custos na Adminis- tração Pública}

Silva e Drumond (2004, p. 3) afirmam que:

fundamentalmente, há duas vertentes precípuas que justificam a apuração de custos no setor público, ambas em sintonia com o que propõe a Administração Pública Gerencial: primeira, a adoção dos custos como critério para a formação de preços públicos e de receitas de prestação de serviços; segunda, a redução de despesas e a conseqüente utilização como mecanismo de aferição de eficiência.

Ao analisar essa segunda utilidade, Alonso (1999, p.39) aponta o esgotamento do modelo de gestão tradicional ou burocrático da administração pública, por enfatizar "os controles formais e o estrito cumprimento das leis" e o surgimento de correntes em defesa de um modelo de gestão de resultados, preocupado com a "melhoria do desempenho".

Segundo Alonso (1999), para que os resultados e energias da administração pública estejam orientados para resultado, é necessário que o perfil dos gerentes e os sistemas de informações estejam totalmente alinhados com essa orientação. O autor (op. cit.) enfatiza que, para avaliar adequadamente o desempenho do serviço público, é crucial que os sistemas de informação do Governo disponham de uma informação gerencial mais refinada que a despesa: os custos.

Nesse sentido, Mileski (2000, p.12) expõe que:

o conhecimento dos custos é condição para o cumprimento do princípio constitucional da transparência e, também, da eficiência, especialmente no sentido estrito da economicidade, que em outras palavras pode ser tomada como sinônimo de custobenefício.

Ao defender a aplicação de custos no setor público, Alonso (1999, p.45) afirma que sua apuração e sua divulgação podem exercer papel de "poderosos instrumentos de controle social", por permitir aos usuários e à auditoria a avaliação da eficiência dos serviços prestados. Dessa forma, o autor destaca a utilidade dos custos como instrumento de detalhamento do planejamento estratégico e de seletividade de cortes orçamentários, quando da necessidade de se tomarem decisões de redução nos gastos públicos.

Para Alonso (1999) os custos estão entre os principais indicadores de desempenho das organizações. Assim, os sistemas de custo desempenham um papel importante nos processos decisórios e na avaliação do desempenho institucional. Diferentemente do setor privado, no setor público as preocupações com a gestão de custos não estão relacionadas com avaliação de estoques ou com apuração de lucros, mas sim com o 
desempenho dos serviços públicos e, conseqüentemente, com o bem-estar da população.

Segundo Slomski (2005, p. 55) “[...] com a evolução da sociedade [...], faz-se necessário que os gestores das entidades públicas conheçam os custos em suas entidades, a fim de poderem tomar as melhores decisões [...]."

Silva (1999) defende que é importante para as entidades públicas estabelecer padrões de eficiência e verificar, ao longo do tempo, se esses padrões são mantidos, mediante uma vigilância constante sobre o detalhamento dos custos e despesas e sua apropriação aos serviços.

A contabilidade de custos levava sempre a idéia de que era um instrumento de auxílio à empresa em sua luta constante por sobrevivência e expansão, porém é técnica de extrema utilidade para o administrador público, especialmente aquele que luta com poucos recursos para atender aos grandes problemas da coletividade (LeONe, 1995, pp. 12-13).

\section{Metodologia}

Kerlinger (1980) afirma que a natureza, ou delineamento da pesquisa, pode ser definida como sendo o plano e a estrutura da investigação, concebidos de forma a obter respostas para as perguntas de pesquisa.

Assim, diante da existência de várias taxonomias de tipos de pesquisa, no presente trabalho será adotada a de Vergara (2003), que propõe classificar as pesquisas quanto aos fins pretendidos e os meios propostos. A autora observa ainda que os tipos de pesquisa "não são mutuamente excludentes", sendo possível utilizá-los de forma combinada (VERGara, 2003, p.49).
Diante do exposto, pode-se classificar a presente pesquisa como exploratória e descritiva quanto aos fins. Exploratória, porque visou buscar a identificação da aplicação de conceitos teóricos sobre contabilidade de custos nas organizações militares prestadoras de serviços do setor público federal, tendo em vista que há pouco conhecimento acumulado na área. Descritiva, pois buscou expor as características do Sistema OMPS, em especial as que se referem ao seu sistema de custeio.

A investigação exploratória, segundo Vergara (2003, p.47), “é realizada em área na qual há pouco conhecimento acumulado e sistematizado". A autora afirma que a pesquisa descritiva consiste em expor as características de uma determinada população ou de determinado fenômeno, podendo estabelecer correlações entre variáveis e definir sua natureza. Por fim, Vergara (2003, p.47) ressalta que a pesquisa descritiva "não tem compromisso de explicar os fenômenos que descreve, embora sirva de base para tal explicação".

Quanto aos meios, trata-se de uma pesquisa bibliográfica, documental e de campo, utilizando-se o estudo de caso como estratégia de pesquisa, de acordo com Yin (2001). Bibliográfica, tendo em vista a importância da sua fundamentação teórica, que tomou por base importantes obras cujo reconhecimento se dá pelo notório saber de seus autores. Documental e de campo porque envolveu a coleta de dados primários no âmbito da organização estudada, segundo a análise de documentos internos não acessíveis ao público em geral, além da aplicação de questionário. Estudo de caso porque concentrou esforços na análise de apenas uma organização, na busca por um maior grau de aprofundamento sobre o assunto. 
A pesquisa bibliográfica consiste no estudo sistematizado desenvolvido com base em material acessível ao público em geral, como livros, revistas e jornais (VERGARA, 2003). Já a investigação documental, segundo Vergara (2003), é feita em documentos conservados no interior de órgãos públicos ou privados de qualquer natureza, ou com pessoas. A pesquisa de campo consiste na investigação empírica realizada no local onde ocorre ou ocorreu um fenômeno, ou onde estão disponíveis os elementos para explicá-lo (VERGARA, 2003). O estudo de caso, afirma Vergara (2003), "é o circunscrito a uma ou poucas unidades, entendidas essas como pessoa, família, produto, empresa, órgão público, comunidade ou mesmo país".

Yin (2001) afirma que existem três fundamentos lógicos que representam as razões para se conduzir um estudo de caso único. O primeiro configura-se quando representa o "caso decisivo", ao se testar uma teoria bem formulada. O segundo é aquele em que o caso representa um "caso raro ou extremo". Por fim, o terceiro fundamento para um estudo de caso único é o "caso revelador". Nessa situação, o pesquisador tem a oportunidade de observar e analisar um fenômeno previamente inacessível à investigação científica (YIN, 2001, p.63).

É possível afirmar que a presente pesquisa, desenvolvida sob a lógica de um estudo de caso único, fundamenta-se na natureza reveladora do caso em estudo, justificando-se, assim, a escolha feita. Diante do exposto, e tendo em vista o objetivo a que se propôs esta pesquisa, o estudo de caso apresentou-se como a técnica mais indicada, por ser a que possibilita alcançar maior nível de profundidade sobre o assunto, permitindo, por conseguinte, maior poder de análise.
O procedimento de coleta de informações da presente pesquisa utilizou-se de dois recursos distintos: dados primários e dados secundários. Segundo Mattar (1999, p.135), os dados primários são "aqueles que não foram antes coletados, estando ainda em posse dos pesquisados, e que são coletados com o propósito de atender às necessidades específicas da pesquisa em andamento". Já os dados secundários são "aqueles que já foram coletados, tabulados,

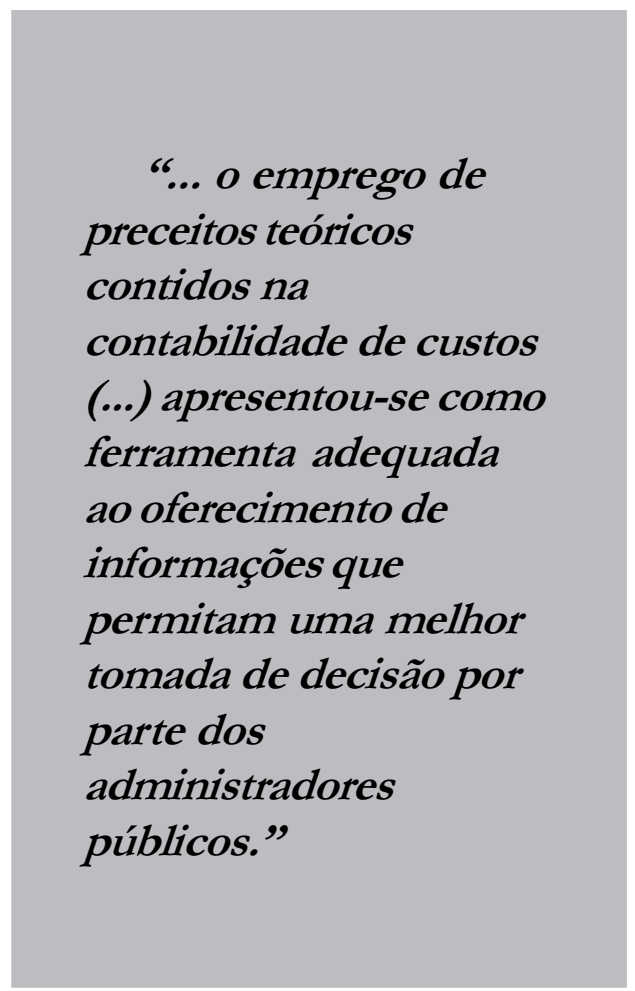

ordenados e, às vezes, até analisados, com propósitos outros aos de atender às necessidades da pesquisa em andamento, e que estão catalogados à disposição dos interessados".

Assim, diante da intenção de alcançar maior grau de profundidade na pesquisa, optou-se pela coleta de dados primários por meio da aplicação de questionário e de entrevista pessoal conduzida pelos 
pesquisadores. O entrevistado é militar, do sexo masculino, com 40 anos de idade. Encarregado da divisão de análise gerencial das OMPS por ocasião do estabelecimento dos GPE, perfaz um tempo total de seis anos na Diretoria de Finanças da Marinha. O referido militar é mestre em Ciências Contábeis pela Universidade Estadual do Rio de Janeiro (UERJ).

Os dados secundários foram coletados na organização, principalmente por meio da pesquisa documental. Ainda na coleta de dados secundários, foram utilizadas diversas publicações, como livros, periódicos, dissertações e, complementarmente, pesquisa via internet, de modo a realizar o levantamento bibliográfico da pesquisa.

\section{O Estabelecimento dos GPE pela DFM}

O estudo de caso foi realizado na Divisão de Análise Gerencial da DFM, órgão central de contabilidade da Marinha, que tem como um de seus principais processos elaborar trimestralmente o relatório econômico-financeiro (REF) das Organizações Militares Prestadoras de Serviços da MB.

Tendo em vista a impossibilidade de mensuração, na prática, dos GPE - uma vez que os custos no Sistema OMPS são classificados em diretos e indiretos -, buscou-se desenvolver um modelo matemático e estatístico para a realização de seu cálculo, baseado em dados históricos, tanto financeiros quanto operacionais. Contudo, em face da carência de dados estatísticos suficientes e confiáveis, o estabelecimento conceitual desse modelo não foi tecnicamente viável, por não ser possível identificar um conjunto de variáveis que representasse o nível de atividade da
OMPS e, ao mesmo tempo, possuísse uma forte correlação com os gastos incorridos.

Perante o exposto e levando-se em consideração que a introdução de um modelo conceitual estatístico destinado a apurar os Gastos de Posse Estratégica de uma Organização Militar Prestadora de Serviços não possui referencial teórico de semelhante aplicação no serviço público, a DFM elaborou uma estimativa dos GPE de todas as OMPS com base nos seguintes parâmetros:

a) foram levantados os custos indiretos anuais das OMPS, no período de 2000 a 2006, excluindo-se a mão-de-obra. A exclusão da mão-de-obra deve-se ao fato de que o pagamento desse insumo de produção advém de fonte de recursos que não se encontra sob a responsabilidade da administração da OMPS. Foi observado que os custos indiretos das OMPS se comportaram, em sua grande maioria, como fixos (e.g., água, energia elétrica, manutenção de equipamentos, manutenção de instalações, qualificação/capacitação da mão-de-obra direta etc.), de forma que uma redução do nível de atividade a zero, por um curto período, provavelmente pouco reduzirá o valor desses gastos;

b) foram levantadas as despesas administrativas anuais das OMPS, no período de 2000 a 2006, excluindo-se a mão-deobra, pelo motivo exposto acima. Foi observado que as despesas administrativas das OMPS, de modo semelhante aos custos indiretos, também se comportaram, em sua grande maioria, como fixas (e.g., energia elétrica dos setores administrativos, qualificação/capacitação da mãode-obra administrativa etc.), de forma que uma redução do nível de atividade a zero também pouco afetará o seu montante;

c) os valores anuais dos custos indiretos e das despesas administrativas levantados 
no Siafi para o período de 2000 a 2006 foram atualizados monetariamente para janeiro/2007 com base no IPCA (Índice Nacional de Preços ao Consumidor Amplo), divulgado pelo IBGE;

d) com base nesses valores monetariamente atualizados, foram calculados os valores médios anuais dos custos indiretos e das despesas administrativas; e

e) os GPE foram apurados para cada OMPS com base no somatório dos custos indiretos médios anuais, acrescidos das despesas administrativas médias anuais.

Assim, com base nesses parâmetros, foram estimados os GPE da OMPS, evidenciados no Quadro 1.
Em seqüência, os valores dos GPE calculados para cada OMPS foram comparados à soma dos custos indiretos com as despesas administrativas, registrados no Siafi em 2006. Os resultados dessa comparação encontram-se consolidados no Quadro 2, a seguir. Ressalta-se que os valores foram condensados por categoria de OMPS (industrial - I; ciência e tecnologia - C; e hospitalar $-\mathrm{H})$.

Diante do exposto, percebeu-se que os resultados estimados para os GPE, de um modo geral, encontravam-se bem próximos aos patamares de custos indiretos e despesas administrativas registrados no Siafi pelas OMPS no exercício anterior (2006), corrigidos pela inflação do período, indicando

Quadro 1: Gastos de Posse Estratégica (GPE) das OMPS estimados pela DFM

\begin{tabular}{|c|c|c|c|}
\hline OMPS & $\begin{array}{c}\text { CUSTOS } \\
\text { INDIRETOS }(*) \\
\text { (valor médiode } 2000 \text { a 2006) } \\
\text { (A) }\end{array}$ & $\begin{array}{c}\text { DESPESAS } \\
\text { ADMINISTRATIVAS }(*) \\
\text { (valor médio de } 2000 \text { a } 2006 \text { ) } \\
\text { (B) }\end{array}$ & $\begin{array}{c}\text { GASTOS DE } \\
\text { POSSE ESTRA TÉGICA } \\
\left(\text { GPE) ESTIMA DOS }\left({ }^{*}\right)\right. \\
(\mathrm{A})+(\mathrm{B})\end{array}$ \\
\hline AMRJ & $44.945 .257,53$ & $6.216 .994,19$ & $51.162 .251,72$ \\
\hline BACS & 3.573 .180 .40 & $611.157,29$ & 4.184.337.69 \\
\hline BAeNSPA & $7.855 .412,89$ & $404.543,13$ & $8.259 .956,02$ \\
\hline BFLa & $704.780,89$ & $381.221,50$ & $1.086 .002,39$ \\
\hline BNA & $3.159 .271,30$ & $2.151 .242,17$ & $5.310 .513,46$ \\
\hline BNN & $2.510 .407,21$ & $122.851,41$ & $2.633 .258,62$ \\
\hline BNRJ & $21.014 .927,66$ & $594.931,53$ & $21.609 .859,19$ \\
\hline BNVC & $928.862,46$ & $333.147,29$ & $1.262 .009,75$ \\
\hline CAM & $1.355 .789,26$ & $352.022,52$ & $1.707 .811,77$ \\
\hline СЕТМ & $2.233 .389,73$ & $65.523,20$ & 2.298 .912 .93 \\
\hline CRSECFN & $834.876,25$ & $465.138,00$ & $1.300 .014,25$ \\
\hline LFM & $3.783 .831,45$ & $2.340 .698,77$ & $6.124 .530,22$ \\
\hline CASNAV & $1.946 .178,34$ & $451.480,34$ & $2.397 .658,68$ \\
\hline CTMSP & $24.949 .438,12$ & $21.154 .643,38$ & 46.104.081,50 \\
\hline IEAPM & $2.493 .980,63$ & $290.165,82$ & $2.784 .146,46$ \\
\hline IPqM & 1.229 .005 .92 & $1.056 .270,86$ & 2.285 .276 .78 \\
\hline HCM & $1.419 .187,98$ & 482.467 .42 & $1.901 .655,40$ \\
\hline HNB e & $1.530 .733,82$ & $493.482,18$ & $2.024 .216,00$ \\
\hline HNB ra & $3.050 .435,66$ & $464.233,89$ & $3.514 .669,55$ \\
\hline HNLa & $613.631,93$ & $283.857,50$ & $897.489,44$ \\
\hline HNMD & 27.052 .754 .84 & 7.287 .472 .25 & $34.340 .227,09$ \\
\hline HNNa & $1.212 .393,50$ & $389.498,07$ & $1.601 .891,58$ \\
\hline HNRe & $1.138 .837,87$ & $487.858,22$ & $1.626 .696,08$ \\
\hline HNSa & $1.594 .866,64$ & $503.181,77$ & $2.098 .048,42$ \\
\hline OCM & $1.375 .340,54$ & $274.429,42$ & $1.649 .769,96$ \\
\hline PNNSG & $3.020 .740,80$ & $1.180 .438,33$ & $4.201 .179,12$ \\
\hline Tota is & 165.527 .513 .62 & 48.838 .950 .45 & 214.366 .464 .07 \\
\hline
\end{tabular}

(*) Todos os valores foram atualizados monetariamente para JAN/2007 pelo IPCA.

Fonte: Relatório Econômico-Financeiro (REF) das OMPS $-1^{\circ}$ Trimestre de 2007 
OMPS-I/C/H

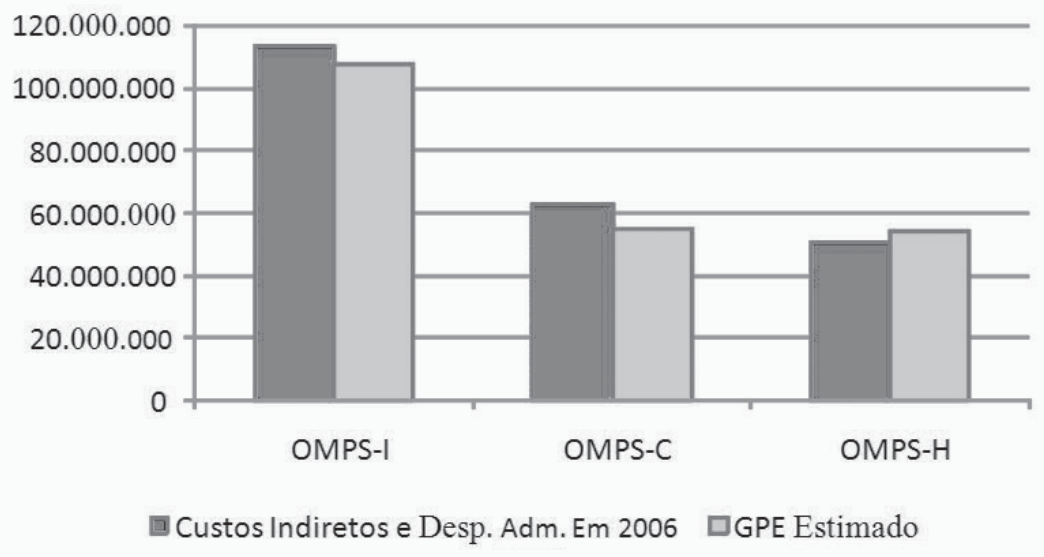

\section{Gráfico 1: Valores dos GPE calculados para cada OMPS}

que os valores estimados encontravam-se consistentes.

Após essa etapa, segundo o entrevistado, foi estabelecida a definição formal dos GPE, a seguir:

Gastos de Posse Estratégica (GPE) de uma OMPS correspondem aos valores totais dos gastos a serem incorridos, pela $\mathrm{MB}$, para a manutenção e o funcionamento das OMPS consideradas indispensáveis, em uma situação hipotética, de inexistência de serviços a serem prestados, ou seja, com um nível de atividade igual a zero.

Como próximo passo no processo de consolidação dessa iniciativa, encaminhouse expediente a cada uma das OMPS solicitando a avaliação dos valores estimados dos seus GPE, com base nas experiências práticas e nas atuais estruturas de gastos daquelas organizações, visando a sua ratificação ou retificação.

Segundo o entrevistado, entre os motivos que poderiam levar às retificações estavam: a) Os valores históricos registrados no SIAFI são inconsistentes. Nesse caso, a fragilidade do sistema de controle interno da OMPS permitiu que, no período de 2000 a 2006, fossem lançados dados não consistentes no Siafi, acarretando uma estimativa imprecisa para os GPE. Por exemplo, classificações incorretas de custos e despesas, violação do regime de competência, falta de lançamentos no Siafi.

b) A estrutura de gastos da OMPS sofreu alterações, para mais ou para menos, nos últimos anos. Nessa situação, a aquisição de novos equipamentos e/ou a baixa de outros considerados obsoletos, a elevação ou redução significativa dos valores dos contratos de prestação de serviços de natureza contínua, bem como a incorporação de novas atividades e/ou o cancelamento de antigas rotinas podem ter feito com que a estrutura de gastos da OMPS fosse alterada nos últimos exercícios financeiros, acarretando uma estimativa dos GPE defasada em relação à atual realidade da OMPS. Por exemplo: revitalização e/ou reaparelhamento da organização. 
c) A OMPS incorre em gastos que, apesar de serem diretos, não são variáveis, tendo em vista que não poderiam deixar de existir, mesmo que a OMPS paralisasse as suas atividades produtivas durante certo período. São gastos que, mesmo na hipótese de redução ou de ausência de serviços, continuariam existindo, com o propósito de não permitir a degradação de seus insumos produtivos (e.g., dano de equipamentos/instalações, perda de mão-de-obra direta qualificada etc.), os quais voltarão a ser empregados passado o período de recesso das atividades.

Entre as 26 OMPS, 19 ratificaram os valores estimados pela DFM e sete solicitaram a sua retificação (três OMPS solicitaram o seu aumento e quatro, a sua redução).

Com base nas respostas enviadas pelas OMPS, obtiveram-se os valores constantes do quadro comparativo (Quadro 2).
Após a definição dos valores dos GPE das Organizações Militares Prestadoras de Serviços, a DFM encaminhou relatório ao Conselho Financeiro e Administrativo da Marinha (Cofamar) contendo esses valores, a fim de obter a aprovação por parte do referido conselho. Assim, na 136 reunião do Cofamar, foram aprovados os valores denominados "Gastos Estratégicos das OMPS", estimados para cada uma delas, que passaram a servir de parâmetro para as análises de desempenho das referidas organizações.

Ressalta-se aqui, conforme informado pelo entrevistado, que os valores estabelecidos para os GPE são atualizados anualmente pela Diretoria de Finanças da Marinha, tendo como base o IPCA, e submetidos à avaliação das OMPS, visando à ratificação ou retificação, levando-se em consideração a experiência prática e a estrutura de gastos em vigor.

\section{Quadro 2: Comparativo entre os GPE estimados e os GPE ratificados/ retificados pelas OMPS}

\begin{tabular}{|c|c|c|c|}
\hline OMPS & $\begin{array}{c}\text { GPE ESTIMADOS PELA } \\
\text { DFM (A) }\end{array}$ & $\begin{array}{l}\text { GPE RA TIF IC AD OS OU RETI FI CADOS } \\
\text { PELAS OMPS (B) }\end{array}$ & $\begin{array}{l}\text { DI FER ENÇA } \\
\text { (B-A) }\end{array}$ \\
\hline AMRJ & $51.355 .326,74$ & $51.355 .326,74$ & 0,00 \\
\hline $\mathrm{BACS}$ & $4.295 .300,61$ & $4.295 .300,61$ & 0,00 \\
\hline BAeNSPA & $8.276 .112,27$ & $13.538 .596,18$ & $5.262 .483,91$ \\
\hline BFLa & 1.092 .341 .50 & 1.092 .341 .50 & 0.00 \\
\hline BNA & $5.310 .513,46$ & $5.310 .513,46$ & 0,00 \\
\hline $\mathrm{BNN}$ & $2.633 .258,62$ & $2.633 .258,62$ & 0,00 \\
\hline BNRJ & $21.609 .859,19$ & $21.609 .859,19$ & 0,00 \\
\hline BNVC & 1.291 .922 .70 & 2.600 .000 .00 & 1.308 .077 .30 \\
\hline CAM & $1.711 .240,18$ & $1.711 .240,18$ & 0,00 \\
\hline СЕTM & 2.301 .495 .66 & 2.301 .495 .66 & 0.00 \\
\hline CRepSup Esp & $1.307 .107,28$ & $1.307 .107,28$ & 0,00 \\
\hline CFN & & & \\
\hline LFM & $6.232 .094,74$ & $6.232 .094,74$ & 0,00 \\
\hline CASNAV & $2.420 .345,01$ & $857.749,40$ & $1.562 .595,61$ \\
\hline CTMSP & 47.391 .234 .01 & 63.353 .920 .40 & 15.962 .686 .39 \\
\hline IEAPM & $2.806 .333,13$ & $2.806 .333,13$ & 0,00 \\
\hline $\mathrm{IPqM}$ & 2.323 .175 .87 & $2.323 .175,87$ & 0,00 \\
\hline $\mathrm{HCM}$ & 1.924 .646 .69 & 1.924 .646 .69 & 0.00 \\
\hline $\mathrm{HNBe}$ & $2.047 .739,45$ & $2.047 .739,45$ & 0,00 \\
\hline HNBra & $3.546 .031,56$ & 1.375 .112 .07 & 2. 170.919 .49 \\
\hline HNLa & $917.131,01$ & $644.939,41$ & $272.191,60$ \\
\hline HNMD & $34.436 .519,98$ & $34.436 .519,98$ & 0,00 \\
\hline $\mathrm{HNNa}$ & $1.617 .498,56$ & $1.617 .498,56$ & 0,00 \\
\hline HNRe & $1.636 .747,57$ & $1.636 .747,57$ & 0,00 \\
\hline HNSa & $2.117 .486,58$ & $2.117 .486,58$ & 0,00 \\
\hline $\mathrm{OCM}$ & $1.658 .047,21$ & $255.330,08$ & $1.402 .717,13$ \\
\hline PNNSG & 4.251 .523 .49 & 4.251 .523 .49 & 0,00 \\
\hline TOTAL & $216.511 .033,06$ & $216.511 .033,06$ & $17.124 .823,78$ \\
\hline
\end{tabular}

Fonte: Relatório Econômico-Financeiro (REF) das OMPS $-1^{\circ}$ Trimestre de 2007 
Cada OMPS pode solicitar sua retificação caso, no ano anterior, sua estrutura de gastos tenha sofrido significativas alterações pelos motivos retromencionados.

O entrevistado afirmou, ainda, que entre as possíveis aplicações do GPE destacam-se:

a) a indicação do nível necessário de comprometimento dos recursos orçamentários da $\mathrm{MB}$ com a manutenção das estruturas das OMPS, cerca de $\mathrm{R} \$ 233,6$ milhões/ano. Sendo assim, esse dado é levado em consideração por ocasião do planejamento dos recursos orçamentários a serem destinados às atividades operacionais daquelas organizações, as quais se relacionam, basicamente, com a manutenção dos meios navais, com o desenvolvimento de ciência e tecnologia e com o sistema de saúde da Marinha; e

b) o dimensionamento da estrutura fixa das OMPS, que deve ser compatível com o seu nível de atividade, representado pelos custos variáveis referentes aos serviços prestados e/ou produtos vendidos. Esse confronto, analisado de acordo com o ramo de atividade de cada OMPS, objetiva evitar a existência de gastos estruturais superdimensionados em relação à sua atividade-fim. Nesse sentido, o dimensionamento dos GPE torna visível uma das principais parcelas dos gastos que se pretende reduzir, ou seja, a fixa. Ademais, os esforços empreendidos visando à diminuição dos GPE levam, como conseqüência direta, à redução dos índices para a cobrança dos custos indiretos e das despesas administrativas praticados pelas OMPS.

\section{Considerações finais}

O presente estudo teve por objetivo verificar como a Diretoria de Finanças da
Marinha conseguiu estabelecer um novo indicador de desempenho das OMPS, diante da necessidade da Alta Administração Naval de saber qual seria o montante de recursos financeiros a ser disponibilizado para a sobrevivência dessas organizações, em uma situação em que o nível de suas atividades fosse próximo de zero. A referida necessidade justificava-se pelos constantes cortes orçamentários sofridos pela Marinha nos últimos anos, que reduziram, consideravelmente, a capacidade de contratação dos serviços das OMPS. Assim, o problema apresentado à DFM pela Alta Administração Naval era: qual seria o volume de recursos orçamentários necessários para manter uma OMPS, na hipótese de que nenhum cliente encomendasse qualquer produto ou serviço?

Dessa forma, para o alcance do objetivo pretendido neste estudo, buscouse, em primeiro lugar, o embasamento teórico necessário à compreensão do tema em lide, por meio da revisão da literatura, que contribui para a definição de um plano de referência utilizado como elemento balizador do desenvolvimento da pesquisa. Além disso, foi realizada uma análise detalhada dos procedimentos adotados pela DFM no processo de estabelecimento dos GPE.

Diante das características e propósitos deste trabalho optou-se pela adoção do estudo de caso, como estratégia de pesquisa, por possibilitar o alcance de maior profundidade no assunto. $\mathrm{Na}$ coleta de dados foram empregados: realização de entrevista pessoal conduzida pelos pesquisadores; consulta a documentos fornecidos pelo entrevistado; consulta a documentos obtidos de outras fontes, como relatórios internos da Marinha do Brasil, internet etc.; e informações coletadas de forma não estruturada com o entrevistado. 
A estrutura analítica consistiu na descrição do caso estudado, tomando-se por base o depoimento do entrevistado e as informações contidas nos documentos disponíveis, seguida de uma análise qualitativa, em que se procurou relacionar os resultados obtidos no trabalho de campo ao plano de referência desenvolvido. Restringindo-se o campo de observação ao caso estudado e às limitações do estudo, são apresentadas a seguir as conclusões da pesquisa.

Dos resultados encontrados, foi possível depreender que os Gastos de Posse Estratégica, criados pela DFM, estão de acordo com as finalidades principais da contabilidade de custos - conforme pensamento de Backer e Jacobsen (1974) -, uma vez que os referidos indicadores passaram a ser incluídos nos relatórios econômico-financeiros das OMPS, servindo como instrumento de planejamento e tomada de decisão para a Alta Administração Naval, no que tange às prioridades de alocação dos recursos da Marinha.

Assim, verificou-se que o emprego de preceitos teóricos contidos na contabilidade de custos, em especial os que se referem aos custos fixos e variáveis, apresentou-se como ferramenta adequada ao oferecimento de informações que permitam uma melhor tomada de decisão por parte dos administradores públicos, uma vez que revela com maior clareza os pontos de desperdícios cometidos, permitindo, assim, a realocação de recursos em projetos que melhor agreguem resultados para a Marinha e, por conseguinte, para a sociedade.

No mesmo sentido, é possível apontar que o estabelecimento dos GPE, não previstos inicialmente no sistema OMPS, satisfaz a necessidade, ressaltada por Alonso (1999), de uma informação gerencial mais refinada para a avaliação do desempenho do serviço público. Ou seja, ao utilizar os conceitos de custos em relação ao volume de atividade, a DFM realizou um refinamento das informações contidas no sistema de custeio das OMPS, no intuito de atender a uma demanda apresentada pela Alta Administração Naval.

Entretanto, faz-se necessário lembrar que a apuração de custos não encerra, por si só, o problema da avaliação de desempenho das entidades públicas. Segundo Silva e Drumond (2004, p.10),

os trabalhos que melhor representam a preocupação com custos no setor público chamam a atenção para o fato de que o bom desempenho das organizações públicas depende, primeiro, do uso racional dos recursos disponíveis na busca das metas priorizadas nos instrumentos de planejamento e, segundo, de ações que realinhem os objetivos da organização com as aspirações da sociedade.

Portanto, recomenda-se a replicação deste estudo em períodos posteriores, inclusive com a abordagem de variáveis que não foram ainda discutidas neste trabalho, no intuito de ratificar o potencial de utilidade dos GPE no processo decisório da Alta Administração Naval, no que tange à alocação dos recursos orçamentários da Marinha.

(Artigo recebido em dezembro de 2008. Versão final em dezembro de 2008.) 


\section{Referências Bibliográficas}

Alonso, M. Custos no Serviço Público. Revista do Serviço Público - Ano 50, n. 1. Brasília: ENAP, 1999.

Backer, M.; Jacobsen. L. E. Contabilidade de Custos: um enfoque para administração de empresas. São Paulo: McGraw-Hill, 1974.

BrasiL. Comando da Marinha. Secretaria Geral da Marinha. SGM-301 - Normas sobre Administração Financeira e Contabilidade, v. IV, 5. rev. Brasília, DF, 2004.

Bresser-Pereira, L. C. Gestão do setor público: estratégia e estrutura para um novo Estado. In: Bresser-PereIRA, L. C.; SPINK, P. (Orgs). Reforma do Estado e administração pública gerencial. Rio de Janeiro: Editora FGV, 1998.

Conselho Regional de Contabilidade do Estado de São Paulo - CRC - SP. Curso sobre contabilidade de custos, 5 . São Paulo: Atlas , 1992.

FonseCA, F. B. C. Contabilidade de custos em órgãos públicos industriais: um estudo de caso sobre as Organizações Militares Prestadoras de Serviços da Marinha. 2003. 107 f. (Dissertação - mestrado em Ciências Contábeis). Faculdade de Administração e Finanças, Universidade Estadual do Rio de Janeiro, Rio de Janeiro).

Horngren, C. T.; Datar, S. M. e Foster, G. Contabilidade de Custos: uma abordagem gerencial. 11a ed. São Paulo: Prentice Hall, 2005.

Kerlinger, F. N. Metodologia da pesquisa em Ciências Sociais: um tratamento conceitual. São Paulo: EPU, 1980.

Leone, G. S. G. Custos: planejamento, implementação e controle. $3^{a}$. ed. São Paulo: Atlas, 2000.

Maher, M. Cost Accouting: creating value for management. 5a. ed. Boston: Mcgraw-Hill/ Irwin, 1997.

Mattar, F. N. Pesquisa de Marketing: metodologia, planejamento. São Paulo: Atlas, $5^{a}$ ed., v.1, 1999.

Mileski, H. S. Gestão Fiscal Responsável. Brasília: BNDES, 2000.

Silva, I. L.; Drumond, R. B. A Necessidade da Utilização de Sistema de Custos e de Indicadores de Desempenho na Administração Pública. In: Congresso USP de Controladoria e Contabilidade, 4, 2004, São Paulo. Anais eletrônicos... São Paulo: USP, 2004. Disponível em: <http://www.congressoeac.locaweb.com.br/artigos42004/ 128.pdf>. Acesso em 12 jul. 2008.

Vergara, S. C. Projetos e relatórios de pesquisa em administração. 4⿳亠丷a ed. São Paulo: Atlas, 2003.

Yin, R. K. Estudo de Caso: Planejamento e Métodos. 2ª ed. Porto Alegre: Bookman, 2001. Tradução de Daniel Grassi. 


\section{Resumo - Resumen - Abstract}

\section{Contabilidade de Custos na Administração Pública: o Estabelecimento dos Gatos de Posse Estratégica na Marinha do Brasil}

Anderson Soares da Silva, Marcelo David Davis e Alexandre Rodrigues Viveiros

A Marinha do Brasil (MB), alinhada com as reformas propostas pelo Governo Federal na busca de uma administração pública gerencial, passou a utilizar a contabilidade de custos nas suas Organizações Militares Prestadoras de Serviços (OMPS). Entretanto, as recentes restrições orçamentárias, impostas às Forças Armadas, geraram a necessidade de a MB conhecer o nível necessário de comprometimento dos recursos orçamentários a ela provisionados com a manutenção das estruturas das OMPS. Assim, a Diretoria de Finanças da Marinha (DFM) desenvolveu estudos na busca do valor adequado desse montante, o qual se denominou Gastos de Posse Estratégica (GPE). Em síntese, se perquiriu qual seria o volume de recursos orçamentários necessários para manter uma OMPS, na hipótese de que nenhum cliente encomendasse qualquer produto ou serviço. A resposta a essa questão demandaria informações das parcelas fixas e variáveis dos gastos, as quais não se encontram disponíveis nas Organizações Militares Prestadoras de Serviços e no SIAFI, uma vez que ambos não prevêem a obrigatoriedade de os gastos serem apurados como fixos e variáveis. O presente estudo objetivou verificar como a DFM conseguiu estabelecer os Gastos de Posse Estratégica das OMPS, diante da necessidade de saber o montante de recursos a ser disponibilizado para a sobrevivência dessas organizações, em uma situação em que o nível de suas atividades fosse próximo de zero. Dos resultados encontrados foi possível depreender que os GPE, estabelecidos pela Diretoria de Finanças da Marinha, estão de acordo com as finalidades principais da contabilidade de custos - de acordo com a literatura -, contribuindo na tomada de decisão quanto à alocação de recursos da $\mathrm{MB}$.

Palavras-chave: Custos variáveis, Gastos de Posse Estratégica, Avaliação

\section{Contabilidad de Costos en la Administración Pública: El Establecimiento de Gastos por la Posesión Estratégica en la Marina de Brasil}

La Marina de Brasil (MB), en línea con las reformas propuestas por el Gobierno federal en la búsqueda de una gestión de administración pública, ha utilizado la contabilidad de costes en sus Organizaciones Militares Proveedoras de Servicio (OMPS). Sin embargo, las recientes restricciones presupuestarias impuestas a las Fuerzas Armadas, han generado la necesidad de la MB conocer el necesario nivel de comprometimiento de los recursos presupuestarios que se le dotará con el mantenimiento de las estructuras de las OMPS. Por lo tanto, los Directores de Finanzas de la Marina (DFM) han desarrollado estudios en busca del valor apropiado de esa suma, que se llama Gastos de la Posesión Estratégica (GPE). En resumen, si perquirió cuál sería el volumen de los recursos presupuestarios necesarios para mantener una OMPS en la hipótesis de que ningún cliente encomendara cualquier producto o servicio. La respuesta a esa demanda de información de las parcelas de costes fijos y variables, que no están disponibles en OMPS y en SIAFI, ya que ambos no prevén la obligación de que los gastos sean registrados como fijos y variables. Este estúdio tiene por objeto ver cómo la DFM consiguió establecer los GPE de las OMPS, ante la necesidad de conocer la cantidad de recursos disponibles para la supervivencia de estas organizaciones, en una situación en la que el nivel de actividad fuera casi nulo. De los resultados se pudo inferir que los GPE, establecidos por la DFM, están en consonancia con los objetivos principales de la contabilidad de costos, de acuerdo con la literatura - contribuyendo con la toma de decisiones en la asignación de los recursos de la MB.

Palabras Clave: Costos Variables, Gastos de Posesión Estratégica, Evaluación 


\section{Accounting for Costs in Public Administration: The Establishment of the Strategic Possession Expenses in the Brazilian Navy}

The Brazilian Navy (BN), in line with the reforms proposed by the Federal Government in pursuit of a managerial public administration, has used the accounting of costs in their Organizations Military Service Providers (OMSP). However, recent budgetary restrictions imposed on the armed forces have generated the need for $\mathrm{BN}$ to know the necessary level of commitment of budget resources provisioned with the maintenance of the structures of the OMSP. Thus, the Directors of Finance of the Navy (DFN) have developed studies in search of the appropriate value of that amount, which is called Strategic Possession Expenses (SPE). In short, it investigated what would be the volume of budget resources necessary to maintain a OMSP based on the assumption that no customer orders any product or service. The answer to that demands details on the plots of fixed and variable costs, which are not available in OMSP nor in SIAFI, since both do not foresee the obligation of the expenses to be recorded as fixed and variable. This study aimed at how the DFN established the SPE of OMSP, given the need to know the amount of resources being made available to the survival of these organizations, in a situation where the level of activity was near zero. The results could be inferred that the SPE, established by DFN, are in line with the main purposes of accounting for costs in accordance with the literature, contributing in decision making regarding the allocation of resources of the BN.

Keywords: Variable Costs; Strategic Possession Expenses; Evaluation.

Anderson Soares Silva

Bacharel em Ciências Navais - Escola Naval e Mestre em Ciências Contábeis - Faculdade de Administração e Ciências Contábeis/UFRJ. Atualmente trabalha na Diretoria de Finanças da Marinha.

Contato: andersoncapita@yahoo.com.br

Marcelo David Davis

Bacharel em Ciências Navais - Escola Naval e Mestre em Ciências Contábeis - Faculdade de Administração e Finanças/UERJ. Atualmente trabalha na Diretoria de Finanças da Marinha.

Contato: davis@dfm.mar.mil.br

Alexandre Rodrigues Viveiros

Bacharel em Ciências Navais - Escola Naval e Mestre em Ciências Contábeis - Faculdade de Administração e Finanças/UERJ. Atualmente trabalha na Diretoria de Finanças da Marinha.

Contato: viveiros@dfm.mar.mil.br 